\title{
A Geoinformatics-based Framework for Surface Water Quality Mapping and Monitoring
}

\author{
Michelle V. Japitana \\ School of Engineering, University of San \\ Carlos, Cebu City and College of \\ Engineering and GeoSciences, Caraga State \\ University, Butuan City, Philippines \\ mvjapitana@carsu.edu.ph
}

\author{
Marlowe Edgar C. Burce \\ School of Engineering, \\ University of San Carlos, \\ Cebu City, Philippines \\ mcburce@yahoo.com
}

\author{
Chul-soo Ye \\ Image and Vision System Laboratory, \\ Department of Aviation and IT \\ Convergence, Far East University, \\ Gamgok-myeon, Korea \\ csye@kdu.ac.kr
}

\begin{abstract}
The management of water systems must be sustainable, something that requires systematic and comprehensive monitoring. However, the attempts to obtain a comprehensive water quality monitoring (WQM) program in developing countries are challenged due to the lack of an integrated framework and limited resources. At present, the Philippines has no systematized technical and operational monitoring approach, poor coordination and data collection system, and weak law enforcement. On the other hand, Geoinformatics promises a more convenient and cost-effective WQM to complement the traditional method. The goal of this study is to demonstrate how to maximize the use of Geonformatics in developing methods and models to address the lack of spatial trends, timely monitoring, and integrated monitoring framework that could lead to a sustainable WQM system. This study employs remote sensing and GIS technique combined with ground-based water quality data as Geoinformatics-based framework to derive water monitoring and assessment information. Results of this study showed that satellite images can be utilized to derive empirical models to estimate WQ parameters. The validation results showed that the estimated WQ values using the RS-based models have no significant difference when compared with the actual WQ values. Also, the WQ maps derived using Geographic Information System (GIS) were proven useful in providing better representation and analysis of spatial and temporal information that can provide a comprehensive and cost-effective reference for WQ monitoring and assessment.
\end{abstract}

Keywords-landsat; water quality monitoring framework; water quality modeling; water quality trends

\section{INTRODUCTION}

Water sustainability is of high importance, as water is one of the most vital resources. Water and its quality are one of the vital elements in the Sustainable Development Goals (SDGs) of the United Nations (UN) Development Program. Water serves as a common link among other SDGs [1], but the world is not yet on track in achieving water-related SDG indicators. In fact, the attempts to obtain a comprehensive water quality monitoring (WQM) program in developing countries are challenged due to the lack of an integrated framework and limited resources. It is, therefore, reasonable to give full attention to how emerging technologies can aid in transforming current water management and water quality monitoring practices, especially in less-developed countries. Geoinformatics emphasized in a formal approach to handle geoinformation and was described as an integrated approach to GIS, photogrammetry, remote sensing, and cartography [2]. Integration of remotely-sensed data, GPS, and GIS technologies provides a valuable tool for monitoring and assessing waterways [3]. There is a high feasibility of integrating Geoinformatics technologies in the existing water quality monitoring framework. Remote sensing technology has allowed measurements on a global scale over long periods and is now proving useful in monitoring coastal waters [4], estuaries [5], and lakes and reservoirs [6, 7]. Biological oxygen demand (BOD) is among the most common water quality parameters measured using remote sensing [8] while RS-based model development studies for water $\mathrm{pH}$ are very limited. The $\mathrm{pH}$ level is a measure of acid content in water, thus water containing a great deal of organic pollution will generally tend to be acidic [9], while BOD is a measure of the amount of oxygen that bacteria will consume under aerobic conditions while decomposing organic matter [8]. The goal of this study is to develop a Geoinformatics-integrated water quality monitoring framework that can provide comprehensive and cost-effective water quality (WQ) assessments. This study aims to demonstrate the use of remote sensing and GIS technologies for WQ model development and validation, WQ estimation and mapping, and in WQ spatial and temporal trends analysis.

\section{STUDY AREA}

Tubay River is one of the classified Class "A" water bodies in Agusan del Norte, Philippines. Its headstream is the main outlet of Lake Mainit and the river traverses the municipalities of Jabonga, Santiago, and Tubay. There are two major tributaries of the river, the Aciga River is at its upstream portion and the Kinahiluan River at the mid-downstream part. Tubay River is situated in a 22,000-hectare catchment area with diverse land uses that include mining, irrigation and other agricultural uses, fishery, livestock production [10], and mining. The Environmental Management Bureau (EMB) pointed out that Tubay River is a receptor of domestic solid and liquid wastes and other non-point sources of pollution [10]. 


\section{PROPOSED FRAMEWORK}

Figure 1 shows the schematic diagram outlining the proposed Geoinformatics-integrated WQM framework. In the proposed framework, the use of remote sensing and GIS techniques are combined with ground-based water quality data to derive WQ monitoring and assessment information. The developed Geoinformatics-integrated framework is further proposed to be employed to any satellite sensor and WQ of interest. The different components of the proposed framework are described in this section.

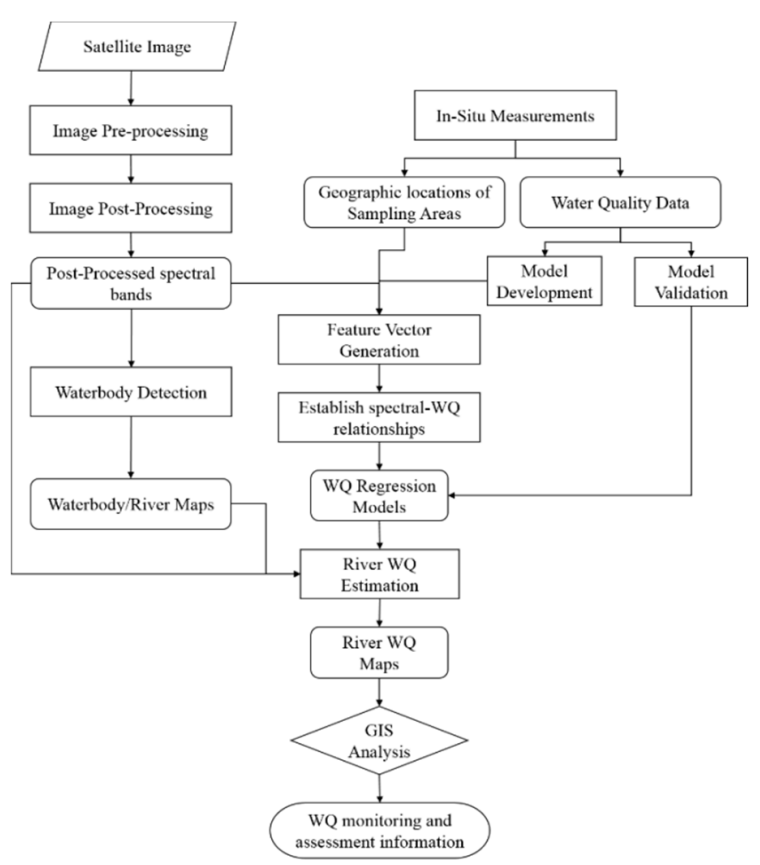

Fig. 1. Proposed Geoinformatics-integrated WQM framework

\section{A. Satellite Data and Water Quality Datasets}

Quarterly WQM data of EMB for the years 2014-2016 were available during the conduct of this study. The dates of measurements of these datasets that closely matched the time of acquisition of the satellite images were considered in the model development, model validation, and WQ estimation and mapping. Also, satellite images with different dates of acquisition were utilized for the model development and for validating the models. Table I shows the list of Landsat images downloaded from USGS Earth Explorer and employed in delineating river map and in estimating $\mathrm{pH}$ and $\mathrm{BOD}$.

TABLE I. INPUT IMAGES FOR WATER BODY DETECTION, MODEL DEVELOPMENT AND VALIDATION, AND WQ ESTIMATION.

\begin{tabular}{|c|c|c|}
\hline Input Image & Acquisition Date & Purpose \\
\hline Landsat 8 (bands 2,3, 5-7) & March 29, 2017 & Waterbody detection \\
\hline Landsat 8 (bands 1-7) & April 19, 2015 & WQ model development \\
\hline Landsat 8 (bands 1-7) & July 26, 2016, & WQ model validation for \\
& August 27, 2016 & pH and BOD \\
\hline & April 19, 2015, & \\
Landsat 8 (bands 1-7) & October 12, 2015, & WQ estimation/mapping \\
& July 26, 2016, & \\
& August 27, 2016 & \\
\hline
\end{tabular}

\section{B. Image Processing}

First, the Landsat images were pre-processed to apply radiometric and atmospheric corrections. Then, the surface reflectance bands were used to perform principal component analysis (PCA), band ratio, and multi-band water indices which were computed using (1)-(3) respectively:

$$
\begin{aligned}
& B R=\rho_{1} / \rho_{5} \\
& M N D W I=\left(\rho_{3}-\rho_{6}\right) /\left(\rho_{3}+\rho_{6}\right) \\
& A W E I_{s h}=\rho_{2}+2.5 \times \rho_{3}-1.5 \times\left(\rho_{5}+\rho_{6}\right)-0.25 \times \rho_{7}
\end{aligned}
$$

where $\rho_{1}$ is ultra-blue (coastal/aerosol) band, $\rho_{2}$ is the blue band, $\rho_{3}$ is the green band, $\rho_{5}$ is the NIR band, $\rho_{6}$ is the SWIR 1 band, and $\rho_{7}$ is the SWIR 2 band of Landsat 8 OLI image.

\section{Waterbody Detection}

The MNDWI and AWEI water indices were classified using minimum distance algorithm to delineate Tubay River (Figure 2) from the Landsat 8 image. The delineated river map is employed as a mask image during river WQ maps generation.

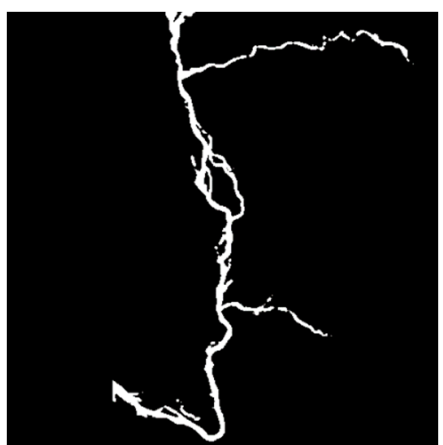

Fig. 2. Derived river map using the combination of MNDWI and AWEI water index

\section{Water Quality Model Development and Validation}

The WQ models for $\mathrm{pH}$ and BOD were derived as described in [11]. The two remote sensing-based WQ models were given as follows:

$$
\begin{aligned}
& p H=8.339-(0.827 \times B R) \\
& B O D=0.382+(28.746 \times \text { PC } 4)
\end{aligned}
$$

The models were then applied to the corresponding input bands and the estimated WQ values for $\mathrm{pH}$ and BOD at the specific locations of the EMB monitoring stations were calculated. To evaluate the reliability of the models, t-tests were performed by comparing the estimated WQ values with that of the actual values measured by the EMB.

\section{E. WQ Estimation and Mapping}

The validated WQ models were applied to the whole input bands of using Band Math of ENVI 5.1 software to derive the WQ images. Then, the WQ images were loaded in QGIS 2.16 software to generate the WQ maps. Using QGIS, non-water areas in the WQ image were masked out using the river map as mask image. And finally, gradient colors and histogram 
stretching were applied for better representation of the spatial and temporal distribution of $\mathrm{pH}$ and $\mathrm{BOD}$ in the study area.

\section{EXPERIMENTAL RESULTS}

The models were validated using two sets of Landsat images, the validation results with the best performance are shown in Tables II and III, which show the estimated versus the actual WQ data and the result of the t-test for $\mathrm{pH}$ and BOD, respectively. The differences between the estimated and actual $\mathrm{pH}$ values are very small having an average value of 0.11 . At EMB stations 3 and 5, the estimated $\mathrm{pH}$ value is very close to the actual $\mathrm{pH}$ value with difference values of 0.04 and 0.08 , respectively. When t-test was performed to compare the two datasets for $\mathrm{pH}$, the result showed that the $\mathrm{t}$ value is less than the critical $t$ value resulting to a $p$-value higher than 0.05 , hence there's no significant difference between the two measurements. Table III shows that the average difference between the two BOD measurements is 0.32. The lowest difference values between the predicted and the actual BODs are at EMB stations 1 and 7 . The t-test results showed a p-value greater than 0.05 , hence the null hypothesis that there is a significant difference between the two groups of measurements can be rejected.

TABLE II. ESTIMATED AND ACTUAL PH

\begin{tabular}{|c|c|c|c|c|c|}
\hline \multirow{2}{*}{ Station } & \multicolumn{2}{|c|}{ pH } & \multirow{2}{*}{ Difference } & \multicolumn{2}{|c|}{ t-test } \\
\hline & Estimated & Actual & & t value & p-value \\
\hline 1 & 8.12 & 7.94 & 0.18 & \multirow{8}{*}{$\begin{array}{c}\mathrm{t}=2.08<\mathrm{t} \\
\text { critical } \\
\text { value }=2.16\end{array}$} & \multirow{8}{*}{0.06} \\
\hline 2 & 8.16 & 7.99 & 0.17 & & \\
\hline 3 & 8.16 & 8.12 & 0.04 & & \\
\hline 4 & 8.33 & 8.05 & 0.28 & & \\
\hline 5 & 8.27 & 8.19 & 0.08 & & \\
\hline 6 & 8.23 & 8.07 & 0.16 & & \\
\hline 7 & 8.29 & 8.05 & 0.24 & & \\
\hline \multicolumn{3}{|c|}{ Average difference value } & 0.11 & & \\
\hline
\end{tabular}

TABLE III.

ESTIMATED AND ACTUAL BOD

\begin{tabular}{|c|c|c|c|c|c|}
\hline \multirow{2}{*}{ Station } & \multicolumn{2}{|c|}{ BOD } & \multirow{2}{*}{ Difference } & \multicolumn{2}{|c|}{ t-test } \\
\hline & Estimated & Actual & & t value & p-value \\
\hline 1 & 0.49 & 0.30 & 0.19 & \multirow{8}{*}{$\begin{array}{c}\mathrm{t}=0.08<\mathrm{t} \\
\text { critical } \\
\text { value }=2.45\end{array}$} & \multirow{8}{*}{0.94} \\
\hline 2 & 0.62 & 1.00 & 0.38 & & \\
\hline 3 & 0.63 & 0.30 & 0.33 & & \\
\hline 4 & 0.61 & 1.00 & 0.39 & & \\
\hline 5 & 0.43 & 0.10 & 0.33 & & \\
\hline 6 & 0.62 & 1.00 & 0.38 & & \\
\hline 7 & 0.62 & 0.40 & 0.22 & & \\
\hline \multicolumn{3}{|c|}{ Average difference value } & 0.32 & & \\
\hline
\end{tabular}

A total of four WQ maps for each $\mathrm{pH}$ and BOD were generated, portraying the spatial and temporal distribution of WQ in Tubay River. Figures 3 and 4 show the 1-month and 6month intervals of $\mathrm{pH}$ maps while Figures 5 and 6 are showing the BOD maps for the same time intervals. Figure 3 showed a slight increase of $\mathrm{pH}$ level in Tubay River, except in some portions near the tributaries. The $\mathrm{pH}$ map for August showed a significant decrease in the downstream of Aciga-Tubay River junction and in the upstream of Kinahiluan-Tubay River junction In Figure 4, the two $\mathrm{pH}$ maps with a 6-month interval show an overall increase in $\mathrm{pH}$ throughout the river except in the downstream of Kinahiluan-Tubay River junction where the red color in the October $\mathrm{pH}$ map depicts a significant $\mathrm{pH}$ level decrease. In analyzing the spatial and temporal distributions of BOD (Figure 5), the WQ maps imply an overall increase of BOD in Tubay River, while the 6-month interval BOD maps (Figure 6) show an overall decrease of BOD levels.



Fig. 3. WQ maps showing the spatial and 1-month temporal distribution of $\mathrm{pH}$ in Tubay River

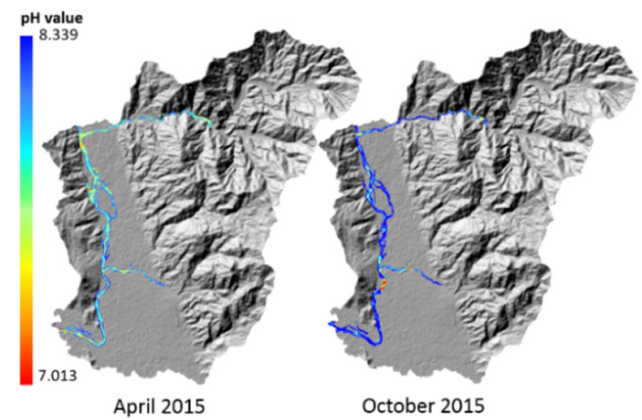

Fig. 4. WQ maps showing spatial and 6-month temporal distribution of $\mathrm{pH}$ in Tubay River



Fig. 5. WQ maps showing spatial and 6-month temporal distribution of BOD in Tubay River

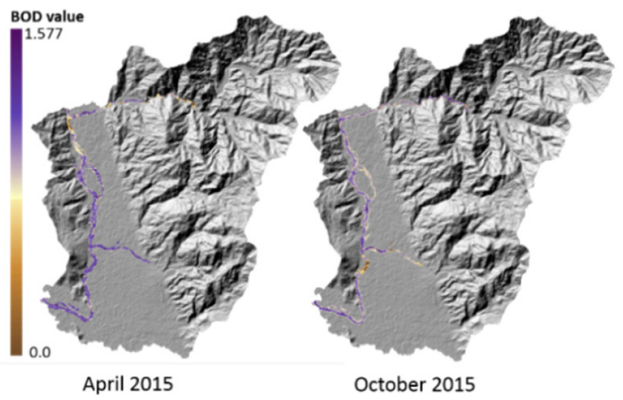

Fig. 6. WQ maps showing spatial and 6-month temporal distribution of BOD in Tubay River 
By visually contrasting the two BOD maps, it can be observed that many locations throughout the river have noticeable changes in BOD levels. These locations include the upstream of Kinahiluan River, downstream of KinahiluanTubay River junction, and downstream of Aciga-Tubay River junction. This kind of visual assessments drawn from Figures 3-6 proves that WQ maps derived using geoinformatics approaches can provide easy spatial and temporal distribution analysis. This possibility is lacking in the traditional pointspecific WQ data. Also, the derived WQ maps can be a good reference to identify the part of the river that did not pass the minimum criteria and those parts of the river where prominent changes are consistently observed. These locations could then be recommended as new sampling areas for the next WQ monitoring campaigns. To demonstrate this practical advantage in using RS-based WQ maps, new random points (RPs) were added in the existing EMB sampling points using the QGIS software as shown in Figure 7. The identification of the locations of RPs is based on the spatial patterns observed in Figures 3-6. From this new set of points, the $\mathrm{pH}$ and BOD levels at four time-scales were then extracted to generate WQ profiles shown in Figures 8-11.



Fig. 7. Map showing the locations of the RPs and EMB sampling points.

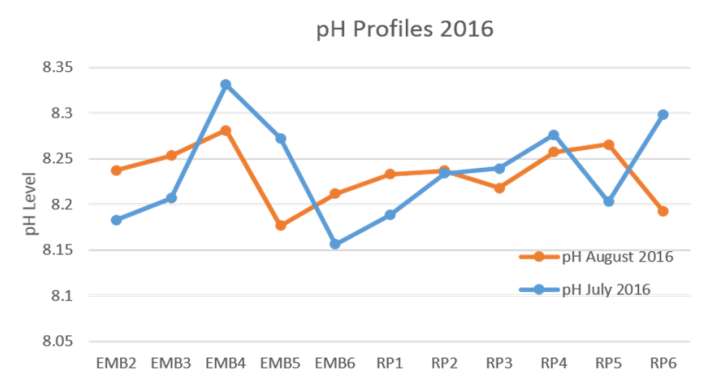

Fig. 8. pH profiles for July and August 2016.
In the 2016 profile graphs of Figure 8, the $\mathrm{pH}$ level almost follows the same pattern except for EMB6, RP3, RP5, and RP6. Also, by comparing the two $\mathrm{pH}$ profiles, it can be observed that there were significant changes in $\mathrm{pH}$ levels in EMB5, RP5, and RP6. In Figure 9, the profile graphs for April and October 2015 show an overall increase of $\mathrm{pH}$ levels except for RP2 where $\mathrm{pH}$ significantly decreased to 7.9. It can be further observed that $\mathrm{pH}$ levels of Tubay River did not vary considerably within a 6-month interval. The average $\mathrm{pH}$ of all $\mathrm{RP}$ and EMB points in Tubay River is is 8.09 and 8.23 during April and October of 2015 respectively.

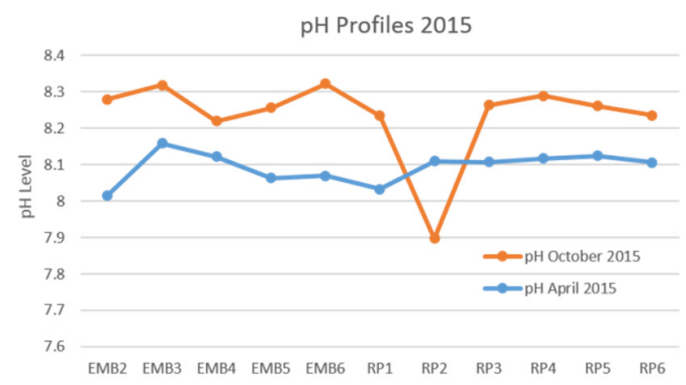

Fig. 9. pH profiles for April and October 2015.



Fig. 10. BOD profiles for July and August 2016.

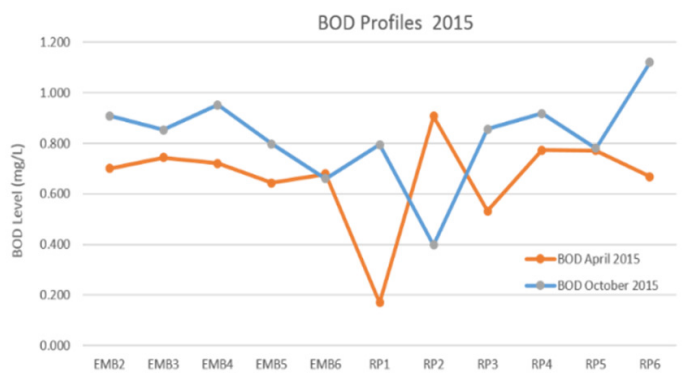

Fig. 11. BOD profiles for April and October 2015.

On the other hand, BOD profiles in Figure 10 show there were remarkable changes in BOD levels between July and August 2016. Notable differences were observed in EMB5, RP1, RP2, and RP6. Slight changes were observed only in EMB2, EMB 3, and RP3 to RP5 while the BOD levels are almost constant at EMB4 and EMB6. In comparing the 6month interval BOD profiles (Figure 11), it can be observed that there's a significant increase in the BOD level in RP1 in contrast to RP2 where a significant decrease in the BOD was 
observed. Overall, an increase in the BOD level was observed in all observing points within the 6-month time difference.

\section{SUMMARY OF FINDINGS}

This study described a Geoinformatics-integrated WQ monitoring framework to demonstrate the practical advantage of using RS datasets like Landsat imageries in analyzing spatial and temporal distributions of WQ parameters. In this study RSbased models for $\mathrm{pH}$ and BOD were developed and validated. The WQ data estimated by the validated models were statistically proven to have no significant difference between the actual measurements taken by EMB. The derived WQ maps showed a good representation of the spatial distribution of $\mathrm{pH}$ and BOD where end-users can visually assess the spatial trends of the WQ parameters throughout the river. The advantages of using RS datasets for WQ modeling and monitoring were also proven useful in this study as it can provide various WQ maps at different temporal scales. Though this study only considered one-month and six-month time differences, it showed that water managers can take advantage of the 15-day return periods of the Landsat missions to augment the existing WQ monitoring data taken using the traditional methods. Furthermore, the WQ maps presented in this study showed that they can be an excellent reference to identify the parts of the river that did not pass the minimum criteria and areas where prominent changes are consistently observed. These locations could then be recommended as new sampling areas for the next WQ monitoring campaigns.

\section{CONCLUSION AND RECOMMENDATIONS}

A simple workflow describing a Geoinformatics-based WQ monitoring framework was presented in this study to perform model development and validation, WQ estimation and mapping, and WQ spatial and temporal trends analysis. Results of this study showed that a Geoinformatics-based WQM, can provide convenient and comprehensive monitoring and assessment of WQ distributions that the traditional pointspecific WQ data don't have. Also, since Landsat imageries can be downloaded for free, the proposed WQM framework is cost-effective and can complement the traditional methods. Though this study presented promising results, it is also important to note that the developed WQM framework is not yet rigorously optimized to achieve a dynamic and comprehensive WQM system. It is rather a simple method outlined to systematically extract spectral information from satellite images to develop WQ empirical models and transform spectral signatures into WQ information. The framework employed in this study aimed to provide an operational method of converting WQ information into visually-convenient reference guides to assess and monitor WQ spatial and temporal trends. There still remains one crucial phase in the proposed WQM framework that has to be implemented and tested for further study, which is the WQ data management and dissemination. The existing WQM scenario in this country is far from realizing the implementation of a centralized and online WQ data management and dissemination. Given the fast-paced advancement of technology, especially in ICT and the Internet of Things, research and development studies must be initiated to keep up with these technologies. Future development steps in line with achieving a dynamic, systematic, and comprehensive WQM system include the development of a comprehensive and interactive web platform for WQ data display and dissemination and the development of an online platform that promotes online WQ data sharing and archiving.

\section{ACKNOWLEDGMENT}

This paper was supported by the Engineering Research and Development for Technology Grant of the Philippine's Department of Science and Technology. Authors would like to thank J. E. B. Cubillas and R. Tacubao of EMB-Caraga for their assistance.

\section{REFERENCES}

[1] A. Bhaduri, J. Bogardi, A. Siddiqi, H. Voigt, C. Vorosmarty, C. PahlWostl, S. E. Bunn, P. Shrivastava, R. Law ford, S. Foster, H. Kremer, F. G. Renaud, A. Bruns, V. R. Osuna, "Achieving Sustainable Development Goals from a Water Perspective", Frontiers in Environmental Science, Vol. 4, pp. 64, 2016

[2] M. Ehlers, "Geoinformatics and digital earth initiatives: a German perspective", International Journal of Digital Earth, Vol. 1, No. 1, pp. 17-30, 2008

[3] J. C. J. Ritchie, P. P. V Zimba, J. H. J. Everitt, "Remote sensing techniques to assess water quality", Photogrammetric Engineering and Remote Sensing, Vol. 69, No. 6, pp. 695-704, 2003

[4] M. Nazeer, J. E. Nichol, "Development and application of a remote sensing-based Chlorophyll-a concentration prediction model for complex coastal waters of Hong Kong", Journal of Hydrology, Vol. 532, pp. 80-89, 2016

[5] M. Hartnett, S. Nash, "An integrated measurement and modeling methodology for estuarine water quality management", Water Science and Engineering, Vol. 8, No. 1, pp. 9-19, 2015

[6] F. Mushtaq, M. G. Nee Lala, A. C. Pandey, “Assessment of pollution level in a Himalayan Lake, Kashmir, using geomatics approach", International Journal of Environmental Analytical Chemistry, Vol. 95, No. 11, pp. 1001-1013, 2015

[7] L. C. Gonzalez-Marquez, F. M. Torres-Bejarano, A. C. TorregrozaEspinosa, I. R. Hansen-Rodriguez, H. B. Rodriguez-Gallegos, "Use of LANDSAT 8 images for depth and water quality assessment of El Guajaro reservoir, Colombia", Journal of South American Earth Sciences, Vol. 82, pp. 231-238, 2018

[8] M. Gholizadeh, A. Melesse, L. Reddi, "A Comprehensive Review on Water Quality Parameters Estimation Using Remote Sensing Techniques", Sensors, Vol. 16, No. 8, pp. 1298, 2016

[9] G. Srivastava, P. Kumar, "Water quality index with missing parameters", International Journal of Research in Engineering and Technology, Vol. 2, No. 4, pp. 609-614, 2013

[10] Environmental Management Bureau - Caraga Region, Tubay River Water Quality Assessment, 2015

[11] M. V. Japitana, M. E. C. Burce, "A Satellite-based Remote Sensing Technique for Surface Water Quality Estimation", Engineering, Technology \& Applied Science Research, Vol. 9, No. 2, pp. 3965-3970, 2019 